\title{
ELECTRICITY GENERATION PORTFOLIO ANALYSIS FOR COAL, GAS AND NUCLEAR PLANT UNDER FUTURE UNCERTAINTIES
}

\author{
Peerapat Vithayasrichareon ${ }^{1}$, Iain MacGill ${ }^{1}$, and Fushuan $\mathrm{Wen}^{2}$ \\ ${ }^{1}$ School of Electrical Engineering and Telecommunications and \\ Centre for Energy and Environmental Markets, University of New South Wales, Sydney, Australia \\ ${ }^{2}$ Institute of Power Economics and Information, School of Electrical Engineering, Zhejiang University, China \\ Email: peerapat@student.unsw.edu.au
}

\begin{abstract}
High and volatile fossil fuel prices, growing concerns over energy security and the risk of climate change have all contributed to revived interest in nuclear power around the world. This is particularly the case in fast developing ASEAN countries. However, there is still considerable uncertainty about the prospects of nuclear power in terms of its economic viability and associated risks given a highly uncertain future energy industry context. This paper employs a stochastic tool based on the Monte Carlo simulation technique to assess the expected generation costs and risk profiles of different electricity generation portfolios of coal, Combined Cycle Gas Turbine (CCGT), and nuclear plants. The tool explicitly incorporates uncertain future fuel and carbon price, and plant capital costs into the analysis. Results from the model enable tradeoffs between expected system generation cost, associated risks and $\mathrm{CO}_{2}$ emissions among generation portfolios to be identified. In this paper the economics of nuclear power in relation to coal and CCGT are evaluated for different portfolio mixes under a number of scenarios of future fuel and carbon prices in the context of the ASEAN region. Results highlight the important role that a carbon price is likely to play in making nuclear power an economic option.
\end{abstract}

\section{KEY WORDS}

Nuclear power, generation portfolio analysis, generation investment under uncertainty, Monte Carlo simulation.

\section{Introduction}

The future role of nuclear power has been one of the most highly contested debates within the electricity industry. Growing concerns over energy security, rising greenhouse gas emissions, and the volatility of fossil-fuel prices have all contributed to increased levels of interest in nuclear power over the past decade. Potentially, nuclear power might significantly contribute to addressing energy security concerns arising from fossil fuel dependence. Growing uncertainties over future fossil-fuel prices and their availability have raised concerns over the security of electricity supply in many countries, in both physical and economic aspects. Nuclear power, on the other hand, is much less sensitive to changes in fuel prices than are fossil-fuel generations duel to the relatively low contribution that fuel costs make to overall generation costs. In addition, the nuclear fuel source, uranium, appears reasonably plentiful and only small volumes are required (due to its high energy density), making it easy to establish strategic inventories [1]. Furthermore, growing international pressures to reduce greenhouse gas emissions from the electricity industry also argue for a greater role for nuclear power given that it has no operating, and only low embodied carbon emissions.

Despite its potential in addressing energy security and climate change, there are significant concerns and uncertainties with nuclear power in areas including radiation risks, operation safety, nuclear weapon proliferation, and waste management. These can all raise barriers to widespread public acceptance of the technology. Another concern is its economic viability; whilst this question is highly contested nuclear power does not appear to currently be economically competitive with coal or gas in many countries. A key issue is the significant uncertainty about the capital costs, lead times and large generation plant builds. Past experience has highlighted that actual construction costs of nuclear projects can be far higher than projected with long delays and hence resulting in high financing charges [2].

From a societal point of view, nuclear power should be assessed under the principle of sustainable development, which states that development to meet the needs of the current human generation should not compromise the ability of future generations to meet their own needs [3]. There are two main viewpoints regarding the role of nuclear power for sustainable development. Nuclear power advocates believe that it is an essential component of sustainable development given its low carbon emissions and energy security contribution, whereas some opponents argue that nuclear power is fundamentally incompatible with sustainable development due to the risks involved.

Recent structural changes in the electricity industry in some countries have had significant implications for generation investment as generators cannot necessarily rely on passing excess costs from poor investments onto customers. For both regulated and competitive industries, investment decision making has become increasingly challenging due to increased volatility and future uncertainty about fuel prices and concern about climate 
change. Efforts have been made by numerous countries to establish mechanisms that put a price on carbon emissions. Imposing prices or taxes on $\mathrm{CO}_{2}$ emissions would ultimately increase the cost of electricity generation. Furthermore, carbon prices would change the merit order of power plants in generation dispatching due to the differences of $\mathrm{CO}_{2}$ emissions intensities among generation plants [4].

However, there is continuing uncertainty surrounding the longer-term impacts of such climate change policies and the level of carbon price likely to be required to deliver effective action on climate change. This future carbon price may prove one of the critical factors in driving generation investment decision making towards lower emission technologies such as nuclear power and renewable because it will increase the operating costs of fossil fuel generation from coal and gas.

This paper employs a generation investment decision support model developed in [5-6] based on the Monte Carlo simulation technique to analyze possible generation portfolios of coal, Combined Cycle Gas Turbine (CCGT) and nuclear plant under fuel, carbon prices and capital cost uncertainties. The model combines stochastic analysis with generation portfolio-based resource mix methods to determine the expected industry electricity generation cost, risk, and $\mathrm{CO}_{2}$ emissions of different possible generation technology portfolios. The economic viability of nuclear in relation to coal and CCGT can also then be evaluated for different carbon prices.

In the next section, we describe nuclear power in the context of the ASEAN region. The detail of the methodology is outlined in section 3. Section 4 present the inputs, parameters and data required. The case study description and results are presented in section 5 . The conclusions are summarized in section 6 .

\section{Nuclear power in ASEAN developing economies}

Many countries around the world have identified nuclear power as a key part of their future generation mix in order to meet their electricity needs. This is particularly the case in rapid developing economies such as many countries in Southeast Asia where continuous socioeconomic development is leading to a rapid growth in the electricity demand.

The Association of Southeast Asian Nations (ASEAN) has been identified to play an increasing important role in world energy markets in the next decades due to their rapid economic expansion, large population size, and energy consumption. Furthermore, with growing pressures to reduce greenhouse gas emissions and concerns over energy security due to fossilfuels dependency among countries in this region, nuclear power has emerged as one of the key options for addressing these concerns. For example, electricity generation in Thailand and Malaysia depends heavily on natural gas, accounting for $67 \%$ and $63 \%$ of the total electricity generation in 2007 respectively [7].

Currently there are no nuclear power plants among ASEAN countries, however countries such as Thailand, Indonesia, Malaysia, the Philippines and Vietnam have expressed interest in nuclear power as one of the key options to meet projected electricity demand whilst addressing energy security issues by diversifying their fossil-fuel mix [8]. Thailand, the Philippines and Vietnam have already included nuclear power as a part of their future generation mix planning. However, there is still considerable uncertainty about the prospects of nuclear power in this region as it still needs to overcome major challenges including financing, site selection, developing safety and security regulations, human resources development, and public acceptance. Another major concern is its economic viability since nuclear power does not appear to be economically competitive with coal and gas given its substantial capital costs.

This paper, therefore, attempts to evaluate electricity generation portfolios of coal, gas, and nuclear plant in the context of the ASEAN region.

\section{Monte Carlo Optimization Model for Assessing Electricity Generation Portfolio}

The generation investment decision support model used in this paper is based on [5-6] which employs the Monte Carlo simulation technique to account for uncertainties when determining the expected generation cost of generation- portfolios. The methodology flowchart of evaluating generation portfolios under uncertainty is shown in figure 1.

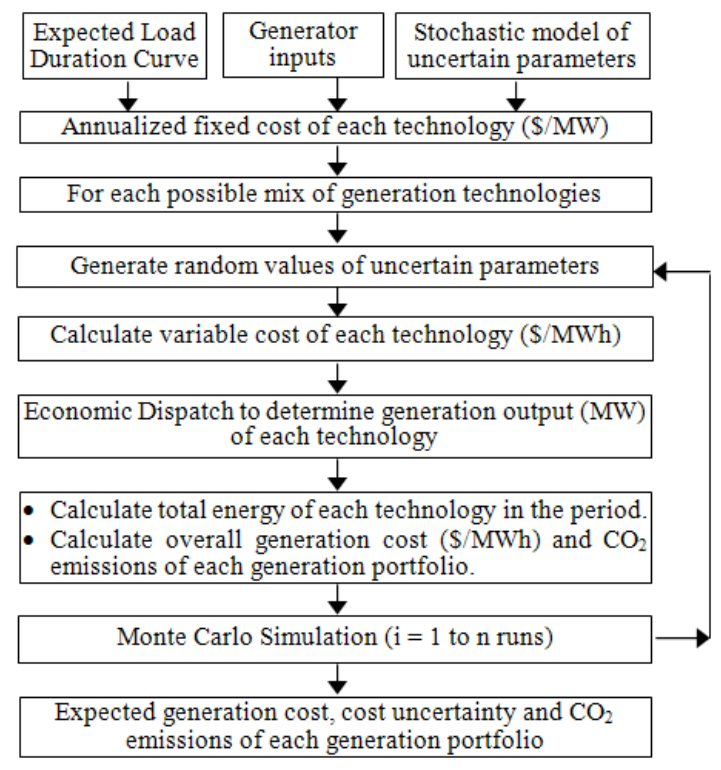

Figure 1. Methodology Flowchart

The model considers a range of generation portfolios by varying the share of each technology in the portfolio 
from $0 \%$ to $100 \%$. The overall generation cost of a generation portfolio is calculated for each set of uncertain parameters. Outputs from the model represent a range of possible generation costs which can be represented by a probability distribution. The cost spread of generation portfolios, represented by the standard deviation, will be referred as the 'cost uncertainty'. This term implies a similar meaning as 'risk' in the economic and finance context. The term 'cost uncertainty' is considered to be more suitable for this study.

This model incorporates the economic operational merits of alternative generation types when determining the generation output of each technology for a given portfolio mix. In particular this approach does not have to assume an operational capacity factor for each technology. With the inclusion of load variability represented by the load duration curve, the generation output of each technology at each hour over a future year can be determined by using the well-established Economic Dispatch based on variable operating costs For each Monte Carlo run, the values of stochastic input parameters are randomly selected from their respective probability distributions, taking into consideration the estimated correlations between them. Note that there is no requirement that these probability distributions be normal or lognormal.

The generation cost consists of annualized fixed and variable costs. The annualized fixed cost is calculated from the overnight capital cost of each generation technology using the Capital Recovery Factor (CRF), as shown in eqn. (1) where $m$ is the plant life and $i$ is the discount rate. The CRF determines the equal amount of regular payments in a present amount of money [9].

$$
\mathrm{CRF}=\mathrm{i}(1+\mathrm{i})^{\mathrm{m}} /\left((1+\mathrm{i})^{\mathrm{m}}-1\right)
$$

The generation output of each technology in each period is determined using the economic dispatch resulting in a least cost operation. The variable cost comprises of operation \& maintenance, fuel and carbon costs as detailed in eqns. (2) and (3) below.

$$
\begin{aligned}
& \text { Fuel cost }=\text { Fuel price } \times \text { Heat Rate } \\
& \text { Carbon cost }=E F \times \text { Carbon price }
\end{aligned}
$$

where $E F$ is the $\mathrm{CO}_{2}$ emissions factor of each technology.

The installed capacity of each technology is determined from the percentage share of such technology in the generation portfolio. The total generation cost for each generation portfolio during each Monte Carlo run is calculated by using eqn. (4).

$$
\mathrm{TC}=\left(\sum_{\mathrm{n} \in \mathrm{N}}\left(\mathrm{FC}_{\mathrm{n}} \times \mathrm{I}_{\mathrm{n}}\right)+\left(\mathrm{VC}_{\mathrm{n}} \times \mathrm{E}_{\mathrm{n}}\right)\right)
$$

where $F C_{n}, I_{n}, V C_{n}$, and $E_{n}$ is the annualized fixed cost, the installed capacity, the variable cost and the energy of technology $n$ respectively.

The total $\mathrm{CO}_{2}$ emission for each generation portfolio is determined according to eqn. (5).

$$
\mathrm{CO}_{2}=\sum_{\mathrm{n} \in \mathrm{N}}\left(\mathrm{EF}_{\mathrm{n}} \times \mathrm{E}_{\mathrm{n}}\right)
$$

\section{Model Inputs}

Inputs into the model include the expected load profile, technological parameters of each generation technology, stochastic model of each uncertain parameter and their correlations. This study considers generation portfolios consisting of different mixes of three generation technology: coal, Combined Cycle Gas Turbine (CCGT), and nuclear under fuel and carbon prices as well as capital cost uncertainty. The share of each generation technology in the generation portfolios ranges from $0 \%$ to $100 \%$ of the total capacity in $20 \%$ increments, and therefore there are 21 possible combinations of generation portfolios to be considered as indicated in Table 1 .

Table 1

Assessed electricity generation portfolios

\begin{tabular}{|c|c|c|c|}
\hline \multirow{2}{*}{ No. } & \multicolumn{3}{|c|}{$\begin{array}{c}\text { Share of technology in } \\
\text { generation portfolio (\%) }\end{array}$} \\
\cline { 2 - 4 } & Coal & CCGT & Nuclear \\
\hline 1 & 0 & 0 & 100 \\
\hline 2 & 0 & 20 & 80 \\
\hline 3 & 0 & 40 & 60 \\
\hline 4 & 0 & 60 & 40 \\
\hline 5 & 0 & 80 & 20 \\
\hline 6 & 0 & 100 & 0 \\
\hline 7 & 20 & 0 & 80 \\
\hline 8 & 20 & 20 & 60 \\
\hline 9 & 20 & 40 & 40 \\
\hline 10 & 20 & 60 & 20 \\
\hline 11 & 20 & 80 & 0 \\
\hline
\end{tabular}

\begin{tabular}{|c|c|c|c|}
\hline \multirow{2}{*}{ No. } & \multicolumn{3}{|c|}{$\begin{array}{c}\text { Share of technology in } \\
\text { generation portfolio (\%) }\end{array}$} \\
\cline { 2 - 4 } & Coal & CCGT & Nuclear \\
\hline 12 & 40 & 0 & 60 \\
\hline 13 & 40 & 20 & 40 \\
\hline 14 & 40 & 40 & 20 \\
\hline 15 & 40 & 60 & 0 \\
\hline 16 & 60 & 0 & 40 \\
\hline 17 & 60 & 20 & 20 \\
\hline 18 & 60 & 40 & 0 \\
\hline 19 & 80 & 0 & 20 \\
\hline 20 & 80 & 20 & 0 \\
\hline 21 & 100 & 0 & 0 \\
\hline
\end{tabular}

\subsection{Expected load profile}

The load profile used in the simulation is based on the actual hourly demand in one of the ASEAN countries. The load duration curve is simplified to 438 segments in which each segment represents the average demand in a 20-hour period to reduce the computation time. This load duration curve is illustrated in Figure 2.

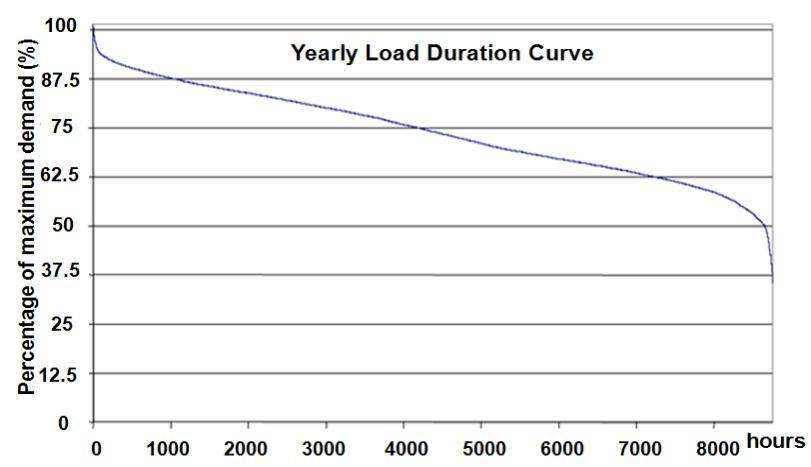

Figure 2. Load duration curve used for the simulation

\subsection{Generator inputs}

Generation costs and characteristics of each technology used in this study are gathered from [2, 10-15], and are shown in Table 2. Note that there are considerable 
uncertainties associated with some of these parameters, and these are addressed below.

Table 2

Technological parameters

\begin{tabular}{|l|c|c|c|}
\hline \multicolumn{1}{|c|}{ Technical parameters } & Coal & CCGT & Nuclear \\
\hline Plant life (years) & 40 & 25 & 40 \\
\hline Capital cost $(\$ / \mathrm{MW})$ & $1,400,000$ & 650,000 & $4,000,000$ \\
\hline Fixed O\&M cost $(\$ / \mathrm{MW} / \mathrm{yr})$ & 43,000 & 25,000 & 100,000 \\
\hline Variable O\&M cost $(\$ / \mathrm{MWh})$ & 3.3 & 1.5 & $2^{\mathrm{a}}$ \\
\hline Average Efficiency $(\%)$ & 42 & 58 & 35 \\
\hline Heat Rate $(\mathrm{GJ} / \mathrm{MWh})$ & 8.571 & 6.206 & 10.900 \\
\hline Emission Factor $\left(\mathrm{t} \mathrm{CO}_{2} / \mathrm{MWh}\right)$ & 0.8 & 0.35 & 0 \\
\hline Expected fuel price $(\$ / \mathrm{GJ})$ & 2.85 & 6.45 & 0.5 \\
\hline
\end{tabular}

\subsection{Stochastic Model of Uncertain Parameters}

Uncertain input parameters in this study consist of gas price, coal price, nuclear fuel price, carbon price, and capital costs. These uncertain parameters are modeled using the lognormal distribution since its fatter-tailed characteristic by contrast with a normal distribution allows for greater potential downside risk arising from high price events. Such downside risk is typically the main concern for utilities and investors making generation investment decisions.

\subsubsection{Fuel price}

The means and standard deviations of gas and coal prices are determined based on their historical prices in [7]. The standard deviations of gas and coal prices used in the model are $30 \%$ and $10 \%$ of their respective mean values. Historically, the fluctuation of gas price has proved greater than that of coal price as indicated by their standard deviation. The approximation of the standard deviations of fuel prices are in line with a number of other studies [16-18]. The standard deviation of the nuclear fuel price is assumed to be quite low, at $10 \%$ of its mean value. Whilst this does not reflect uranium spot price behavior in recent years, we assume significant long-term fuel contracting (associated with the plant and fuel provider), plentiful supplies at current levels of demand and a mature enrichment industry. Furthermore, due to the high density of nuclear fuel which requires only a small amount to generate a unit of electricity, fuel can also be stored onsite for many years of operation. Therefore, it is assumed that there is less uncertainty surrounding the nuclear fuel price.

\subsubsection{Carbon price}

Since the carbon market is yet to fully mature, this study assumes that the expected carbon price is $\$ 20 / \mathrm{tCO}_{2}$ with the standard deviation of $50 \%$ of the expected value. A high value of the standard deviation for the carbon price is assumed to allow for the possibility that the carbon price may vary significantly due to government policies or other external factors.

Table 3 shows the means and standard deviations of gas, coal, nuclear fuel, and carbon prices used for the simulations in this study.

Table 3

Mean and standard deviation ( $\%$ of mean) of uncertain fuel and carbon prices

\begin{tabular}{|c|c|c|c|c|}
\hline & $\begin{array}{c}\text { Carbon } \\
\text { price } \\
\left(\mathbf{\$} / \mathbf{C O}_{\mathbf{2}}\right)\end{array}$ & $\begin{array}{c}\text { Coal } \\
\text { price } \\
\mathbf{( \$ / G J )}\end{array}$ & $\begin{array}{c}\text { Gas } \\
\text { price } \\
\mathbf{( \$ / G J )}\end{array}$ & $\begin{array}{c}\text { Nuclear } \\
\text { Fuel price } \\
(\mathbf{\$} / \mathbf{G J})\end{array}$ \\
\hline Mean & 20 & 2.85 & 6.45 & 0.5 \\
\hline Standard deviation & 10 & 0.285 & 1.935 & 0.05 \\
\hline
\end{tabular}

\subsubsection{Correlation between fuel and carbon prices}

This model also takes into account the correlations between fuel and carbon prices since in practice the movement of gas, coal and carbon prices has exhibited a considerable correlation as evidenced in the EU and UK market. Such correlations have been identified to have a considerable impact on the cost and risk profile of generation portfolios by either moderating or exacerbating the impact of uncertainty $[16,19]$.

The correlation between gas and coal prices for our study is determined based on the historical data and they exhibit a strong positive correlation [7]. However, the empirical correlation between fuel and carbon prices is less evident due to immature carbon markets therefore it is estimated based on a number of recent studies $[16,19$ 21]. The evidence of the EU carbon market suggests that the gas and carbon prices exhibit a positive correlation while the coal and carbon prices exhibit a negative correlation. Intuitively, as gas prices increase coal will become more favorable. As the electricity generation shifts towards coal, $\mathrm{CO}_{2}$ emissions will increase since coal is a carbon intensive technology, and therefore causing the carbon price to rise under the emission trading scheme. It is assumed that the nuclear fuel price has a negligible correlation with gas, coal and carbon prices. Since the fuel cost for nuclear only contributes to about $2 \%$ of the total generation costs [22] therefore correlations would not significantly alter the results. The correlation factors between fuel and carbon prices used in this study are shown in Table 4.

Table 4

Correlations between fuel and carbon prices

\begin{tabular}{|l|c|c|c|c|}
\hline $\begin{array}{c}\text { Correlation } \\
\text { Coefficient }\end{array}$ & $\begin{array}{c}\text { Coal } \\
\text { price }\end{array}$ & $\begin{array}{c}\text { Gas } \\
\text { price }\end{array}$ & $\begin{array}{c}\text { Carbon } \\
\text { price }\end{array}$ & $\begin{array}{c}\text { Nuclear } \\
\text { fuel price }\end{array}$ \\
\hline Coal price & 1 & 0.65 & -0.32 & 0 \\
\hline Gas price & 0.65 & 1 & 0.45 & 0 \\
\hline Carbon price & -0.32 & 0.45 & 1 & 0 \\
\hline Nuclear fuel price & 0 & 0 & 0 & 1 \\
\hline
\end{tabular}

Multivariate lognormal simulation is employed to generate correlated random gas, coal, nuclear fuel, and 
carbon prices from their respective lognormal distributions.
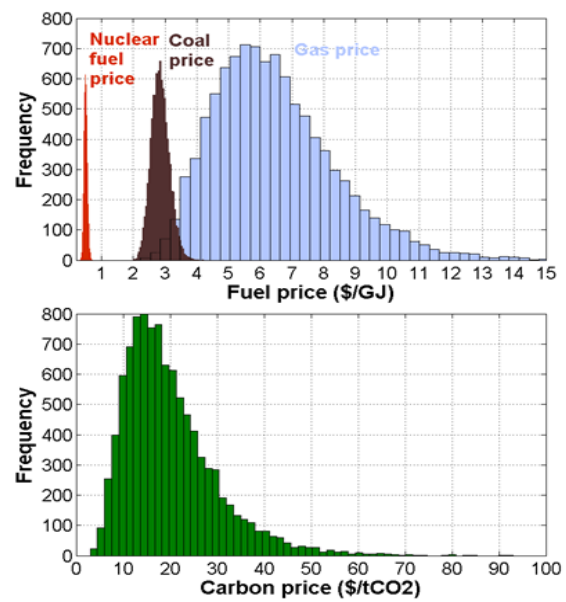

Figure 3. Distributions of sampled gas, coal, nuclear fuel, and carbon prices

The distribution of the sampled gas, coal, nuclear fuel, and carbon prices over 5,000 simulations are shown in Figure 3. The upper graph shows that the distributions of coal and nuclear fuel prices are less spread due to their low volatility compared with that of the gas price. The distributions of gas and carbon prices exhibit longer tail due to higher variances.

The scatter plots of 5,000 samples of gas, coal and carbon prices are also shown in Figure 4. Correlations were verified to be the same as the values specified in Table 4.
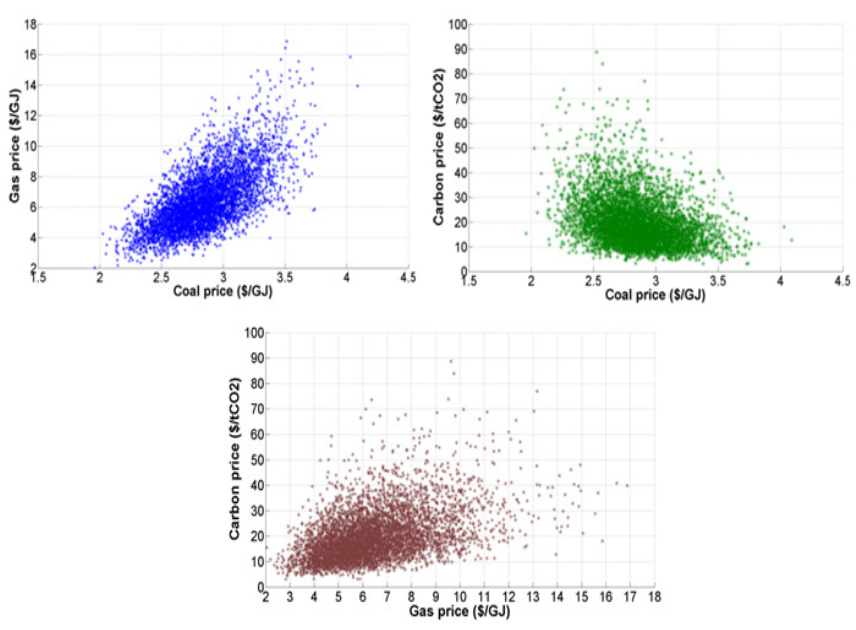

Figure 4. Scatter plots of 5,000 samples of gas, coal and carbon prices

\subsubsection{Capital cost}

The capital cost uncertainty of each generation technology is determined based on the range of capital cost presented in [10]. The standard deviations of the capital costs for coal, CCGT, and nuclear power used in this study is $15 \%$,
$10 \%$ and $35 \%$ of their mean capital costs respectively. The construction costs for nuclear plants are subjected to a greater uncertainty than those of coal and CCGT due to its longer construction time, less mature construction industry and greater regulatory oversight and requirements. Based on the track record, actual costs are often proved far higher than had been projected [2]. Long delays in construction result in high financing costs. Therefore, in this study, the volatility of the nuclear capital costs is assumed to be reasonably higher than those of coal and CCGT. Table 5 summarizes the means and standard deviations of capital costs for each technology.

Table 5

Mean and standard deviation of capital cost of each technology

\begin{tabular}{|l|c|c|c|}
\hline \multicolumn{1}{|c|}{ Capital cost } & Coal & CCGT & Nuclear \\
\hline Mean $(\$ / \mathrm{MW})$ & $1,400,000$ & 650,000 & $4,000,000$ \\
\hline SD $(\%$ of mean) & $15 \%$ & $10 \%$ & $35 \%$ \\
\hline
\end{tabular}

The distribution of the sampled capital cost for each generation technology over 5,000 simulation sare shown in Figure 5. As illustrated in the lower graph, the capital cost spread of nuclear is siginificantly greater than those of coal and CCGT.
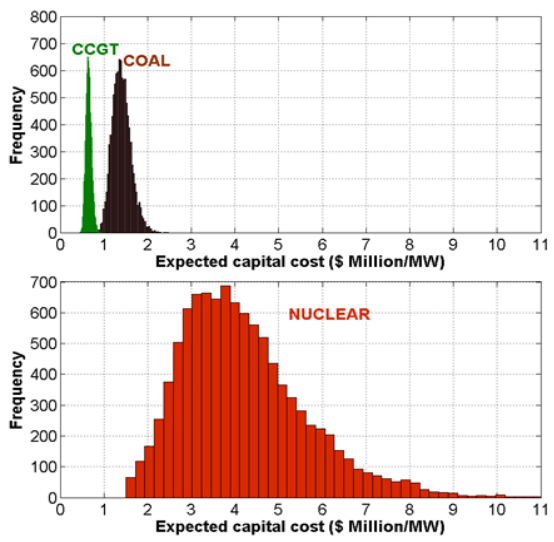

Figure 5. Distribution of sampled capital costs

\section{Simulation results and analysis}

The overall generation cost of generation portfolios consist of different mixes of coal, CCGT and nuclear are simulated given the fuel, carbon prices, and capital cost uncertainties described above. The calculation of the generation cost for each generation portfolio is repeated for 5,000 simulated years of uncertain future fuel price, carbon price and capital costs. The impact of carbon pricing on generation portfolios is also explored by running the simulations for different expected carbon prices. The simulation results consist of the expected generation cost, standard deviation of the generation cost, 
which represents the cost uncertainty, and $\mathrm{CO}_{2}$ emissions of each generation portfolio.

The expected generation cost and the $\mathrm{CO}_{2}$ emissions of every possible generation portfolio are plotted against the corresponding standard deviations, as shown in Figure 6.

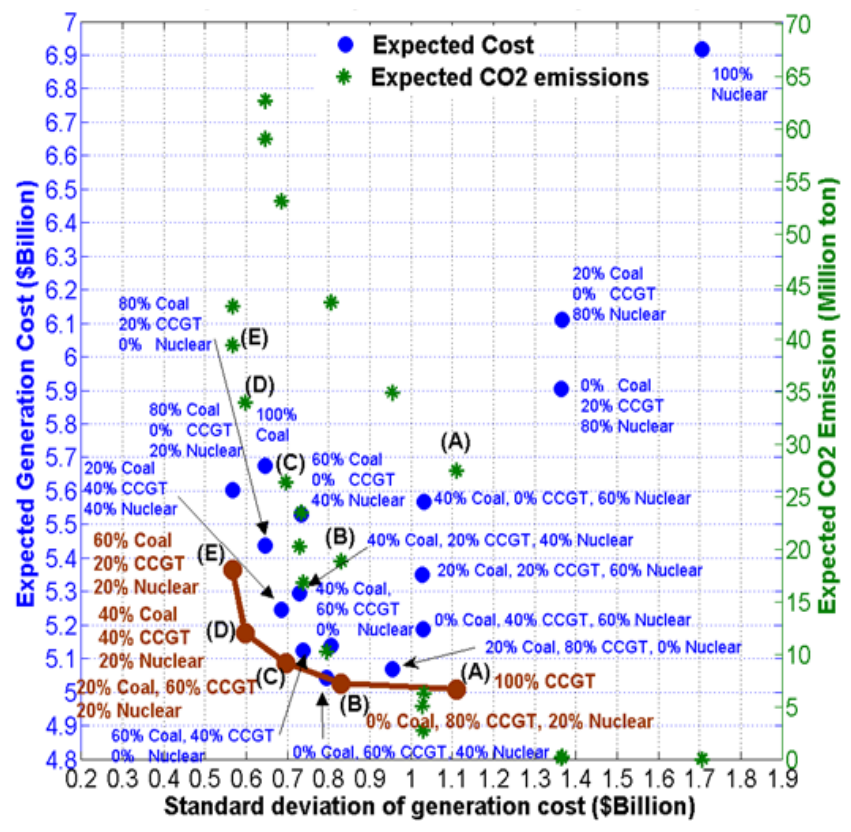

Figure 6. Expected generation cost, cost uncertainty and $\mathrm{CO}_{2}$ emissions

The expected generation cost of each portfolio is represented by the blue dots and the $\mathrm{CO}_{2}$ emission of the corresponding portfolio is represented by the green asterisks.

The Efficient Frontier ${ }^{1}$ which consists of optimal generation portfolios can be constructed, as shown by the solid line in Figure 6. Along the efficient frontier line, the generation cost cannot be reduced without increasing the cost uncertainty and vice versa. Generation portfolios that are not on the efficient frontier can be disregarded in terms of this analysis since their expected generation costs and cost uncertainty are too high in relation to optimal generation portfolios on the efficient frontier.

For the case in which the expected carbon price is $\$ 20 / \mathrm{tCO}_{2}$, there are five optimal generation portfolios on the efficient frontier labeled as portfolio (A) - (E). Although portfolio A, which is $100 \%$ CCGT mix, has the lowest expected generation cost, its cost uncertainty is remarkably high - a result of this portfolio's dependence on highly volatile gas prices. The next lowest cost generation portfolio on the efficient frontier is portfolio $\mathrm{B}$, which consists of $0 \%$ coal, $80 \%$ CCGT, $20 \%$ nuclear mix. Portfolio B has an only slightly higher cost than portfolio

\footnotetext{
${ }^{1}$ Efficient frontier is the concept used in the Mean-Variance portfolio (MVP) theory developed by Markowitz [23] for financial portfolio optimization to analyze the expected returns and risks of financial portfolios.
}

A but its cost uncertainty and $\mathrm{CO}_{2}$ emissions are considerably lower. On the other hand, the generation portfolio which has the least cost uncertainty is portfolio E, which consists of $60 \%$ coal, $20 \%$ CCGT and $20 \%$ nuclear, but its expected generation cost and $\mathrm{CO}_{2}$ emissions are higher than other generation portfolio on the efficient frontier.

By assessing tradeoffs between the expected cost, cost uncertainty and $\mathrm{CO}_{2}$ emissions of optimal generation portfolios on the efficient frontiers, utilities or investors can be assisted in selecting the most appropriate generation portfolio to suit their risk preferences and environmental sustainability objectives.

The cost-risk tradeoff between optimal generation portfolios can also be statistically compared through cumulative probability plots showing their generation cost differences. Figure 7 shows the cumulative probabilities of the generation cost differences between portfolio B and other optimal generation portfolios, which are portfolio C, $\mathrm{D}$, and $\mathrm{E}$. For example, according to the red curve in Figure 7 , there is approximately $62 \%$ likelihood that portfolio B, which comprises of $0 \%$ coal, $80 \%$ CCGT and $20 \%$ nuclear will have a lower cost than portfolio $\mathrm{C}$, which comprises of $20 \%$ coal, $60 \%$ CCGT and $20 \%$ nuclear.

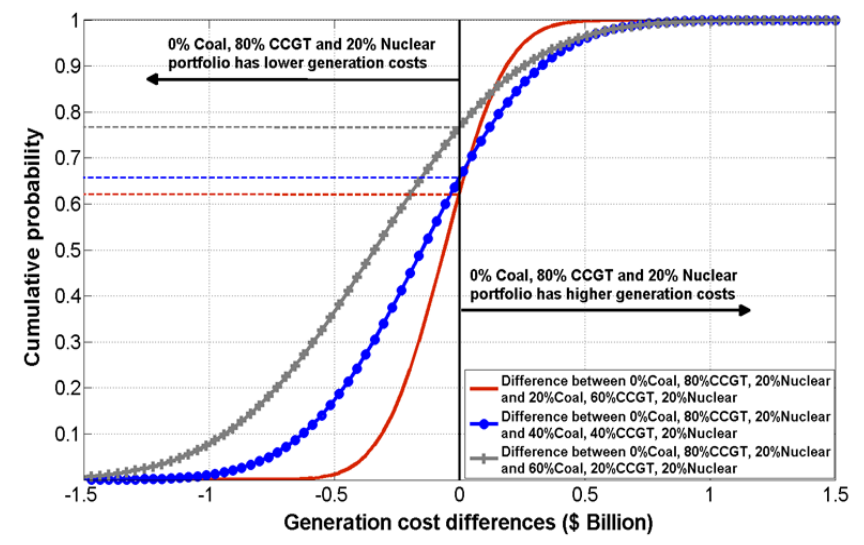

Figure 7. Cumulative probability of optimal generation portfolios

The cost distribution of single technology portfolios and the optimal generation portfolios on the efficient frontier are shown in Figure 8. Based on the cost assumptions used in the model, nuclear plant is the most costly and susceptible technology under fuel and carbon prices as well as capital cost uncertainty as indicated by its cost spread. This is due mainly to its high capital cost.

In previous work [6], it has been demonstrated that the main source of uncertainty for CCGT is fuel price while the dominant source of uncertainty for coal is carbon price fluctuation. In this study, given uncertainty in fuel, carbon prices and capital costs, with an expected carbon price of $\$ 20 / \mathrm{tCO}_{2}$, coal still has the lowest cost uncertainty compared with CCGT and nuclear. Generation portfolios that comprise of a large share of 
coal, therefore, exhibit lower cost uncertainty compared with portfolios that are dominated by CCGT or nuclear.
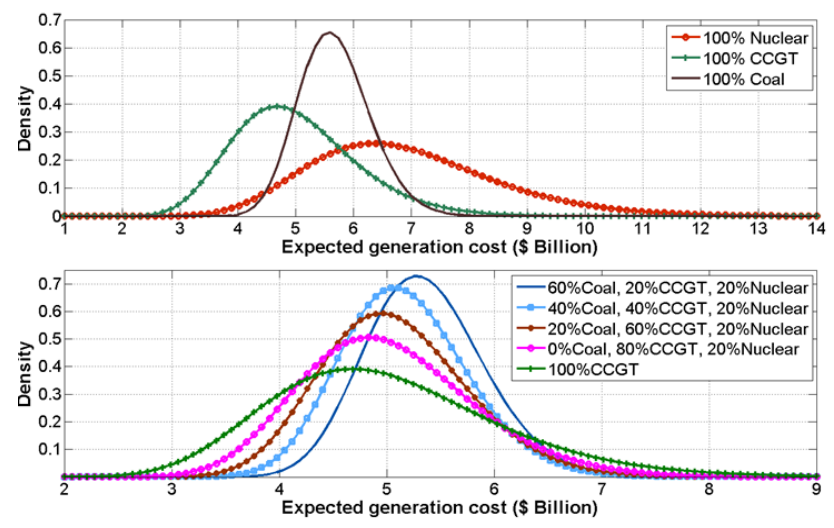

Figure 8. Cost distributions of different generation portfolios

With increased uncertainty about climate change policies and future carbon prices, the impact of carbon pricing can significantly influence the decision making in generation portfolio investment. High carbon prices would make coal, which is a carbon-intensive technology, less favorable compared with other technologies such as CCGT, OCGT, and, in the extreme case, nuclear, which ultimately affects the share of technology in the optimal generation portfolios.

The impact of varying carbon prices on the relative expected cost and cost uncertainty of generation portfolios can therefore be assessed by running the simulations for different expected carbon prices. The efficient frontiers consisting of optimal generation portfolios for different expected carbon prices are shown in Figure 9.

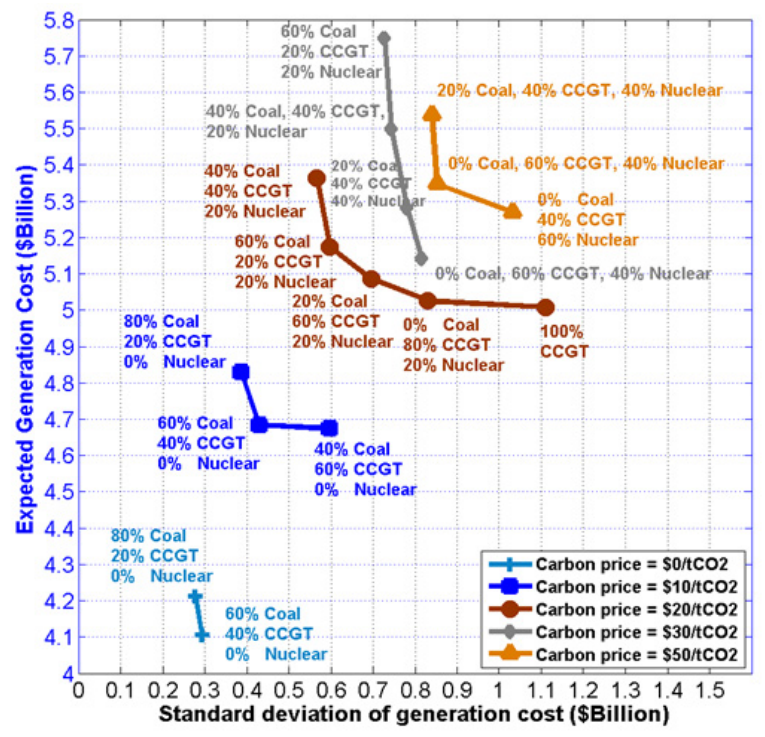

Figure 9. Efficient frontiers for different carbon prices

According to the figure, without imposing a carbon price, there are only two optimal generation portfolios on the efficient frontier, both of which are dominated by coal and without nuclear. At a carbon price of $\$ 10 / \mathrm{tCO}_{2}$, there are three optimal generation portfolios, and they still do not comprise of nuclear. As carbon price reaches $\$ 20 / \mathrm{tCO}_{2}$, portfolios with nuclear begin to feature in the efficient frontier, however CCGT becomes more dominant as the optimal generation portfolios consist predominantly of CCGT. At the same time portfolios with a large share of coal begins to disappear, indicating that coal is becoming less favorable. As the carbon price increases further from $\$ 20 / \mathrm{tCO}_{2}$, generation portfolios with larger shares of nuclear are evidenced on the efficient frontier. At a carbon price of $\$ 50 / \mathrm{tCO}_{2}$, the optimal generation portfolios consist mainly of CCGT and nuclear indicating that at this level of the carbon price nuclear is becoming economically competitive with coal and CCGT.

For low carbon prices, coal is clearly the most favorable generation technology and nuclear is the least economically attractive in terms of both cost and cost uncertainty. As carbon price increases, CCGT and nuclear become more favorable compared to coal therefore portfolios with a large share of coal tend to lie outside the effient frontier for high carbon prices. Without considering the demand-side response, the increase in the carbon price ultimately increases the overall industry cost of electricity generation as well as the cost uncertainty. The economic viablibity of nuclear also improves in relation to coal and CCGT as carbon price increases due its low carbon footprint. Based on simulation results, it seems that in order for nuclear power to have an economically attractively role in future generation portfolios with other fossil-fuel based technologies, the level of the carbon price has to be significant.

\section{Conclusion}

This paper has employed a generation investment decision support model based on the Monte Carlo optimization technique to evaluate electricity generation portfolios consisting of different mixes of three generation technologies: coal, Combined Cycle Gas Turbine (CCGT), and nuclear under the uncertainty of fuel, carbon price and capital costs. Generation portfolios are evaluated based on their expected generation cost, cost uncertainty and expected $\mathrm{CO}_{2}$ emissions. Results from the model enable the optimal generation portfolios to be identified. By assessing tradeoffs among the expected cost, cost uncertainty and $\mathrm{CO}_{2}$ emissions, appropriate generation portfolios can be chosen based on the risk preferences and environmental objectives of utilities and investors.

Under the cost assumptions used in the model, and with a carbon price of $\$ 20 / \mathrm{tCO}_{2}$, results from the model suggest that nuclear is the most costly technology and most susceptible to cost uncertainty compared to coal and CCGT due largely to its high and uncertain capital costs. Hence portfolios which consist largely of nuclear appear 
to have high costs as well as high cost uncertainty and are unattractive on a strictly economic basis.

The economic viability of nuclear power is also evaluated by varying scenarios of the expected carbon price. As the carbon price increases, the economic viability of nuclear also improves in relation to coal and CCGT, due to its carbon-free characteristic. High carbon prices would significantly increase the cost and cost uncertainty of coal and, to some extent, CCGT, resulting in the improvement of nuclear power's competitiveness. Results suggest that the level of the carbon price has an influential role in the economic viability of nuclear power.

Nuclear power has the potential to enhance energy security and mitigate the risk of climate change caused by the electricity industry. However, without mechanisms to establish an environmental externality which put a price on $\mathrm{CO}_{2}$ emissions, it is unlikely that nuclear power will be economically competitive with other fossil-fuel based generation technologies due to its extremely high and uncertain capital costs. More generally wider concerns of safety, nuclear proliferation and waste handling still need to be addressed for this technology to deliver on its potential.

\section{Acknowledgements}

This work was supported in part by an Australian Research Council (ARC) Discovery Grant DP0878580 exploring the interactions between emissions trading and wholesale electricity markets. In addition, Peerapat Vithayasrichareon would like to acknowledge the financial support provided by the Australian Government under the Endeavour Awards to support his Ph.D. study at the University of New South Wales.

\section{References}

[1] H.-H. Rogner and A. McDonald, Nuclear Energy - Status and Outlook, Internaional Atomic Energy Agency 2007.

[2] MIT, Update of the MIT 2003 Future of Nuclear Power, Massachusetts Institute of Technology 2009.

[3] I. MacGill, S. Healy, and H. Outhred, Is there a sustainable future for nuclear power?, Power and Energy Magazine, IEEE, vol. 4, 2006, pp. 63-74.

[4] C. Qixin, K. Chongqing, X. Qing, and Z. Jin, Power Generation Expansion Planning Model Towards LowCarbon Economy and Its Application in China, IEEE Transactions on Power Systems, vol. 25, 2010, pp. 111725.

[5] P. Vithayasrichareon, I. MacGill, and F. Wen, Monte-Carlo optimization framework for assessing electricity generation portfolios, in Power Engineering Conference, 2009. AUPEC 2009. Australasian Universities, 2009, pp. 1-6.

[6] P. Vithayasrichareon, I. F. MacGill, and F. Wen, Electricity Generation Portfolio Evaluation for Highly Uncertain and Carbon Constrained Future Electricity Industries, presented at the IEEE PES General Meeting, Minneapolis, 2010.

[7] IEA, Electricity Information 2009, International Energy Agency, Paris 2009.
[8] IEA, World Energy Outlook 2009:, OECD/IEA, Paris 2009.

[9] H. G. Stoll, Least-Cost Electric Utility Planning: John Wiley \& Sons, 1989.

[10] NEA/IEA, Projected Costs of Generating Electricity, 2005 Update, OECD Publisher, Paris, Paris 2005.

[11] IEA, Energy Technology Perspectives 2008: Scenario \& Strategies to 2050, OECD/IEA, Paris 2008.

[12] IEA, Fossil Fuel-Fired Power Generation: Case Studies of Recently Constructed Coal and Gas-Fired Power Plants, OECD/IEA, Paris 2007.

[13] R. Doherty, H. Outhred, and M. O'Malley, Establishing the Role That Wind Generation May Have in Future Generation Portfolios, IEEE Transactions on Power Systems, vol. 21, 2006, pp. 1415-1422.

[14] MIT, The Future of Nuclear Power: An Interdisciplinary MIT Study, Massachusetts Institute of Technology 2003.

[15] D. Feretic and Z. Tomsic, Probabilistic analysis of electrical energy costs comparing: production costs for gas, coal and nuclear power plants, Energy Policy, vol. 33, 2005, pp. 513.

[16] F. A. Roques, D. M. Newbery, and W. J. Nuttall, Fuel mix diversification incentives in liberalized electricity markets: A Mean-Variance Portfolio theory approach, Energy Economics, vol. 30, 2008, pp. 1831-1849.

[17] W. Blyth and M. Yang, Impact of Climate Change Policy Uncertainty in Power Investment, International Energy Agency, Paris 2006.

[18] H. Laurikka, Option value of gasification technology within an emissions trading scheme, Energy Policy, vol. 34, 2006, pp. 3916-3928.

[19] S. Awerbuch and M. Yang, Efficient Electricity Generating Portfolios for Europe, in Analytical Methods for Energy Diversity and Security: A tribute to Shimon Awerbuch M. Bazilian and F. A. Roques, Eds., ed London: Elsevier, 2008.

[20] R. Green, Carbon tax or carbon permits:The impact on generators' risks, Institute for Energy Research and Policy, University of Birmingham 2007.

[21] M. Yang and W. Blyth, Modelling Investment Risks and Uncertainties with Real Options Approach, International Energy Agency 2007.

[22] IAEA, Nuclear Power and Sustainable Development, International Atomic Energy Agency, Vienna 2009.

[23] H. Markowitz, Portfolio Selection, The Journal of Finance, vol. 7, 1952, pp. 77-91. 